\title{
Towards sustainable membrane filtration of palm oil mill effluent: analysis of fouling phenomena from a hybrid PAC-UF process
}

\author{
Mutiu Kolade Amosa ${ }^{1}$
}

Received: 23 April 2016/Accepted: 3 October 2016/Published online: 19 October 2016

(c) The Author(s) 2016. This article is published with open access at Springerlink.com

\begin{abstract}
Sustainability of a membrane process depends on many factors of which fouling mitigation is the most central. Because membrane fouling phenomenon is very complex, extent of fouling potential of a feedwater with respect to a membrane has to be identified right from the design stage. This will acquaint engineers with the proper fouling mitigation measures during operation. This study presents a preliminary fouling data from the ultrafiltration of biotreated palm oil mill effluent (POME) after an upstream adsorption process. The flux decline is studied in a typical constant-pressure experiments with a cross-flow ultrafiltration of biotreated POME through Sartocon ${ }^{\circledR}$ polyethersulfone membranes (MWCOs 1, 5 and $10 \mathrm{kDa}$ ) at applied pressures of 40,80 and $120 \mathrm{kPa}$. Results are examined, within the frame of the common blocking mechanisms and it was found that the blocking index $\eta$ decreased from 2 to 0 . Pore blocking phenomenon was successively observed from complete blocking $(\eta=2)$ down to cake filtration $(\eta=0)$, and the early blockage of the pores and a formation of a cake resulted in a limiting cake height. Thus, cake filtration could be best used to explain the fouling mechanisms of biotreated POME on the ultrafiltration membranes based on the $R^{2}$ values at all applied pressures. This demonstrates that the fouling was as a result of gradual reversible cake deposition which could easily be removed by less onerous cleaning methods. In addition, it could be concluded that the upstream
\end{abstract}

Mutiu Kolade Amosa

mutiu.amosa@wits.ac.za; dhakisalafi@live.com

1 NRF/DST Chair: Sustainable Process Engineering, School of Chemical and Metallurgical Engineering, University of the Witwatersrand, Private Bag X3, WITS 2050, Johannesburg, South Africa adsorption reduced the particulate deposition on the membrane surface.

Keywords UF membranes - Hermia's blocking models . Fouling - Sustainability · Pore blocking index .

Cake filtration - Biotreated POME

\section{Introduction}

Amidst the population explosion which is proportional to the escalating urbanization and industrialization, concerns over fresh water shortages have increased steadily (Amosa et al. 2013; Jami et al. 2013). Amongst many solutions proffered, reclamation and reuse programs appear to be the potential means of bringing new life to wastewater. This has made reclaimed water to be deemed as a reliable and drought-proof non-traditional source of water (FattaKassinos and Michael 2013; Jami et al. 2013). Recently, most industrial wastewater is increasingly being considered for reclamation and reuse rather than being discharged, with the aid of modern purification technologies. Potentials of modern water treatment technologies are being explored in the removal of harmful contaminants that have previously made industrial wastewater unfit for reuse to make the water perfectly safe for a variety of reuse purposes. This in turn helps in minimizing the huge volume of daily fresh water being diverted for industrial use, and ultimately reduces costs, and watercourse pollutions.

One of the most important separation technologies pertinent to reclamation and reuse programs is the membrane technology which has stood up to scrutiny over the years (Amosa et al. 2013, 2016a, c; Jami et al. 2013). However, pore blocking or fouling, which is its main drawback is still being studied. Fouling hampers membrane 
processes for wastewater treatment as it affects membrane lifetime, permeate flux and the overall performance of the filtration process. Therefore, fouling remains one of the crucial factors governing the overall performance of membrane filtration systems.

Ultrafiltration (UF) is one of the pressure-driven separation processes by which some components of a solution are separated from the solvent by a semipermeable membrane. This is applied in a variety of separations in the pharmaceutical, chemical, food, petroleum and gas, pulp and paper, and environmental industries. Ultrafiltration process is less complex compared with nanofiltration or reverse osmosis processes. It is relatively athermal, involves no phase change, non-destructive to sensitive components such as proteins, requires low hydrostatic pressure, and can be operated at low temperatures. These are the excellent UF advantages over other separation processes.

Most investigative studies have focused on demonstrating the need for the treatment of POME for reuse or discharge that meets the standards set by the regulatory authorities, there is currently still insufficient understanding of the internal membrane fouling that leads to flux decline. Membrane fouling phenomena remains complex and related to membrane-particle and particle-particle interactions, which is consequently governed by the physicochemical condition of the solution, system hydrodynamics, and membrane properties and structure (Rezaei et al. 2014).

The blocking filtration laws were first studied by Herman and Bredée (Hermans and Bredée 1935, 1936). Hermia derived the so called "intermediate blocking" law which had previously been considered totally empirical (Hermia 1966). Hermia revised all blocking laws including "complete blocking" and "filter cake" laws and reformulated the four laws in a common frame of power-law nonnewtonian fluids (Hermia 1982).

Just one of these blocking mechanisms is usually assumed for analysing experimental results; the standard blocking or cake filtration phenomenon. Nonetheless, it is reasonable to expect all or some of these classical blocking processes to act successively in a complete flux decline filtration process involving a complex feed. Assuming that the process of deposition is ruled by the standard blocking mechanism during all the time range.

The transition between different blocking models, is gradual and complex in the central steps but can be approximated by a standard blocking process (Bowen et al. 1995). The authors however observed the stages of (a) blocking of the smallest pores by all particles, (b) covering of the inner surfaces of bigger pores, (c) superimposition of some particles on already present particles with some others directly blocking some of the pores, (d) then the initialization of cake build-up. In actual fact, the four phases are superimposed because, relatively there exist a more or less wide pore size distribution.

It is nomenclatural to consider the initial steps of the filtration process which should correspond to a complete blocking pattern.

In our previous work (Amosa et al. 2016c), we reported the successful biotreated POME reclamation using the PAC-UF system. Now, a systematic study was carried out to describe in terms of the blocking mechanisms the successive steps in the loss of flux or membrane permeability during cross-flow ultrafiltration of biotreated POME. Effects of different operational parameters, such as the transmembrane pressures (TMP) and membrane MWCO, were evaluated with a focus on the identification of the phenomena that limit the mass transfer. This will fully aid the understanding of water reclamation from POME and sustainability of the process. In addition, such knowledge will assist in making the right decisions at the planning and design stages about the appropriate operational conditions and cleaning methods. Since a solution (biotreated POME) with relatively uniform viscosity was utilized throughout this study, a Newtonian behaviour of the fluid was assumed. As such, filtration equations for constant-pressure filtration of Newtonian fluids-solids mixtures were fully considered.

\section{Theoretical background of fouling phenomena}

In order to control particulate fouling at the design stage, as well as for monitoring during a plant operation, methods utilised in evaluating the particulate content of feed-water in predicting membrane fouling are essential. Soluble and colloidal materials are assumed to be responsible for membrane pore blockage, whilst suspended solids account mainly for the cake layer resistance (Judd 2011).

The fouling tendency, usually represented by silt density index (SDI) and modified fouling index (MFI), involve a constant-pressure membrane filtration tests, thus, the indices are calculated from the experimentally determined relationship between filtration time and cumulative permeate volumes (Boerlage et al. 2002; Huang et al. 2008). In both tests, feed-water is filtered through a $0.45 \mu \mathrm{m}$ microfiltration membrane in a dead-end flow at constant pressure. However, there are arguments that SDI cannot be used for mathematical modelling in predicting the flux decline due to particulate fouling owing to the fact that it is not based on a distinction between blocking and cake filtration mechanisms. On the contrary, MFI is based solely on cake filtration mechanism and is dependent on particle size through the Carman-Kozeny equation for specific cake resistance (Boerlage et al. 2002, 2003; Iritani 2013). 
In order to accurately measure and predict particulate fouling, it has been proposed that specific MFI be investigated with respect to a specific membrane since $\mathrm{MFI}_{0.45}$ cannot represent all membranes. This is due to the fact that principal factors such as retention of smaller particulates, proof of cake filtration, membrane pore size, surface morphology, and material must be considered in such investigations (Amosa 2015a; Boerlage et al. 2002).

\section{Blocking filtration models}

The study of blocking filtration phenomena, especially the complete and standard blocking laws (Boerlage et al. 2002), was pioneered in 1935 as reported by Hermans and Bredée (1936) and Bowen et al. (1995). However, the reformulation of the four blocking mechanisms in a common frame of power-law non-newtonian fluids was revised by Hermia (1982). The four simplified fouling models have been used for evaluating the fouling of membranes by various types of water chemistries and/or matrices with complex compositions (Huang et al. 2008). Equation 1 serves as a general formula for all the blocking models (Boerlage et al. 2002, 2003; Huang et al. 2008) with Fig. 1 depicting the mechanisms of the respective blocking model:

$\frac{\mathrm{d}^{2} t}{\mathrm{~d} V^{2}}=k\left(\frac{\mathrm{d} t}{\mathrm{~d} V}\right)^{\eta}$,

where $k$ and $\eta$ are dimensionless numbers that are related to the respective fouling phenomena. More explicitly, the blocking index $\eta$ is a dimensionless filtration constant that characterizes the mode of the fouling model involved, while $k$ is the resistance coefficient which depends on the system, the filter medium, and the conditions of filtration. Cake filtration, intermediate blocking, standard blocking and complete blocking filtration models will have respective characteristic $\eta$ values of $0,1,1.5$, and 2 as briefly reviewed in the succeeding sub-sections. It must however be noted that in this study, blocking filtration equations for filtration of power-law non-Newtonian fluids-solids mixtures (Iritani 2013), were reduced to those for filtration of Newtonian fluids-solids mixtures by putting the flow behaviour index as unity and the fluid consistency index as the Newtonian viscosity.

\section{Complete pore blocking}

The sealing of membrane pores by the particles reaching the membrane indicates complete pore blocking. It is idealized that none of the particles are superimposed upon other particles during filtration (devoid of any cake layer formation), or on top of the solid area of the membrane surface between the pores (Bowen et al. 1995; Huang et al. 2008). The blocked surface area is proportional to the filtrate volume in this blocking type. This idealized blocking scenario requires that all foulants accumulate exclusively on the membrane pores in that all the involved particle sizes are larger than the membrane pores (Iritani 2013). Huang et al. (2008) opined that this is an unlikely scenario in membrane filtration as model simulation reports and experimental evidence suggest that deposition of foulants does not solely occur on membrane pores, especially when low-pressure membranes (LPMs) are considered. The characteristic equation for complete blocking phenomenon for constant pressure filtration is given by (Bowen et al. 1995):

$\frac{\mathrm{d}^{2} t}{\mathrm{~d} V^{2}}=A_{\mathrm{c}}\left(\frac{\mathrm{d} t}{\mathrm{~d} V}\right)^{2}$,

where $A_{\mathrm{c}}$ represents the constant of the complete blocking law. The linearized model follows the mathematical relation (Iritani 2013; Mohammadi et al. 2003):

$Q=Q_{\mathrm{i}}-K_{\mathrm{b}} V$

where $Q$ is the volumetric permeate flow rate $(\mathrm{L} / \mathrm{h}), Q_{\mathrm{i}}$ is the initial volumetric permeate flow rate $(\mathrm{L} / \mathrm{h}), V$ represents

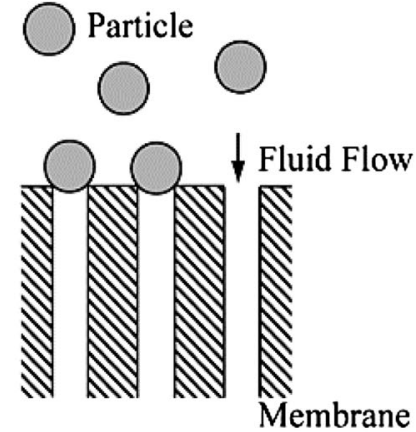

(a) Complete blocking

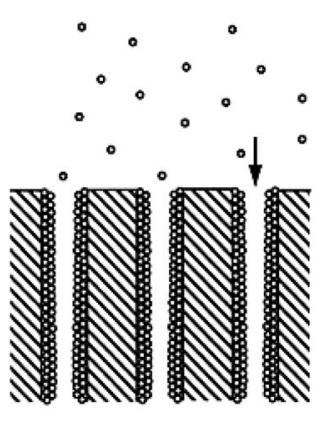

(b) Standard blocking

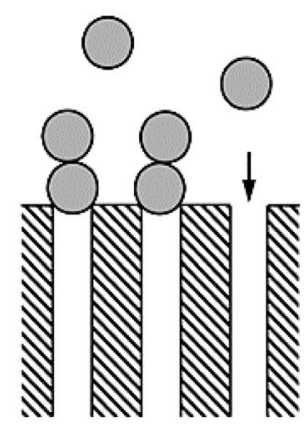

(c) Intermediate blocking

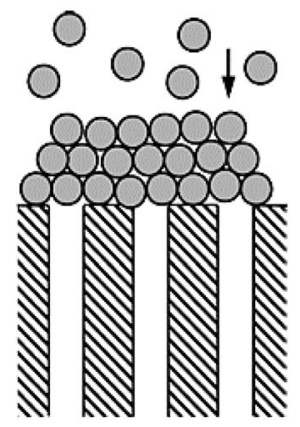

(d) Cake filtration

Fig. 1 Schematics of the blocking filtration laws (Iritani 2013) 
the permeate volume $(\mathrm{L})$, and $K_{\mathrm{b}}$ is the filtration constant for complete blocking model.

\section{Standard pore blocking}

This is the attachment of small particles at the internal walls of the pores resulting in the constriction of the membrane pores. Here, the pore volume decreases proportionally to the permeate volume passing through the membrane pores, and the pore diameter is enormously larger than the particle diameter thereby depositing on the pore walls and reducing the pore volume through the plugging of the pores. The following characteristic equation is used to describe the standard blocking phenomenon (Bowen et al. 1995):

$\frac{\mathrm{d}^{2} t}{\mathrm{~d} V^{2}}=\frac{2 B}{\sqrt{J_{\mathrm{v}}(0)}}\left(\frac{\mathrm{d} t}{\mathrm{~d} V}\right)^{3 / 2}$,

where $B$ is the constant for the standard blocking model. The linearized equation is as follows (Iritani 2013; Mohammadi et al. 2003):

$\sqrt{Q}=\sqrt{Q_{\mathrm{i}}}-\left(K_{\mathrm{s}} \sqrt{Q_{\mathrm{i}}} \cdot \frac{V}{2}\right)$,

$K_{\mathrm{s}}$ in the equation represents the model constant for standard pore blocking.

\section{Intermediate pore blocking}

In this case, it is assumed that each particle reaching the membrane may not only block membrane pores as similar to complete pore blocking, but will also attach to other particles on the membrane surface. This indicates the occurrence of competition between the membrane pores and the existing particles on the membrane surface for the approaching particles and thus, reduce the actual number of particles that can block the pores. Although the permeate volume is proportional to the blocked area, the blocking is less restrictive in that not every particle necessarily blocks the membrane pore. In this fouling type, membrane-contaminants attraction is favoured leading to irreversible fouling in that it is more resistant to the hydrodynamic forces applied during cleaning. Therefore, the characteristic equation should be (Bowen et al. 1995):

$$
\frac{\mathrm{d}^{2} t}{\mathrm{~d} V^{2}}=\frac{A_{\mathrm{i}}}{J_{\mathrm{v}}(0)}\left(\frac{\mathrm{d} t}{\mathrm{~d} V}\right)
$$

$A_{\mathrm{i}}$ is the constant of the intermediate blocking law. The linearized version of the model is as follows (Iritani 2013; Mohammadi et al. 2003):

$\frac{1}{Q}=K_{\mathrm{i}} t+\frac{1}{Q_{\mathrm{i}}}$, where $t$ is the filtration time, and $K_{\mathrm{i}}$ represents the intermediate blocking model constant.

\section{Cake layer formation (cake filtration)}

This is the formation of a cake layer outside the external membrane surface due to the increase in the hydraulic resistance encountered during membrane filtration. With cake filtration, it is assumed that the fouling type does not affect the pore structure of the membrane (Huang et al. 2008). This is the universal type of membrane fouling in water treatment, as it does not depend upon the actuality of favourable membrane-contaminant attractions thereby leading to reversible fouling, in contrast to intermediate pore blocking model (Huang et al. 2008). The characteristic equation of the cake filtration process can be represented by (Bowen et al. 1995):

$\frac{\mathrm{d}^{2} t}{\mathrm{~d} V^{2}}=\frac{C}{2 J_{\mathrm{v}}^{2}(0)}\left(\frac{\mathrm{d} t}{\mathrm{~d} V}\right)^{0}$,

$C$ represents the constant of the cake filtration law and the simplified model follows the mathematical relation (Iritani 2013; Mohammadi et al. 2003):

$\frac{1}{Q}=\frac{1}{Q_{\mathrm{i}}}+K_{\mathrm{c}} V$,

where $K_{\mathrm{c}}$ is the constant for cake filtration model.

Analysis of the filtration data plots in various forms of the aforementioned blocking models can aid in revealing the mechanisms that may be dominating the fouling process.

\section{Materials and methods}

\section{Unit and membrane}

The experimental unit applied in this study is shown in Fig. 2. The hybrid system consists of a feedwater sedimentation tank, adsorption reactor, a micron filter, a peristaltic pump, a membrane module and a permeate tank. The geometrical configurations and rationale for each unit has been fully discussed elsewhere (Amosa et al. 2016a, c; Jami et al. 2013). Three Sartocon slice UF cassette membranes of polyethersulfone material with molecular weight cut-off (MWCO) of 1, 5 and $10 \mathrm{kDa}$ were investigated. Each of the membrane cassettes have an effective surface area of $0.1 \mathrm{~m}^{2}$ and were supplied by Sartorius Stedim biotech Sdn. Bhd., Malaysia.

\section{Feedwater preparations}

The raw feedwater (biotreated POME) quality was analysed, and the concentrations of most of the contents were 


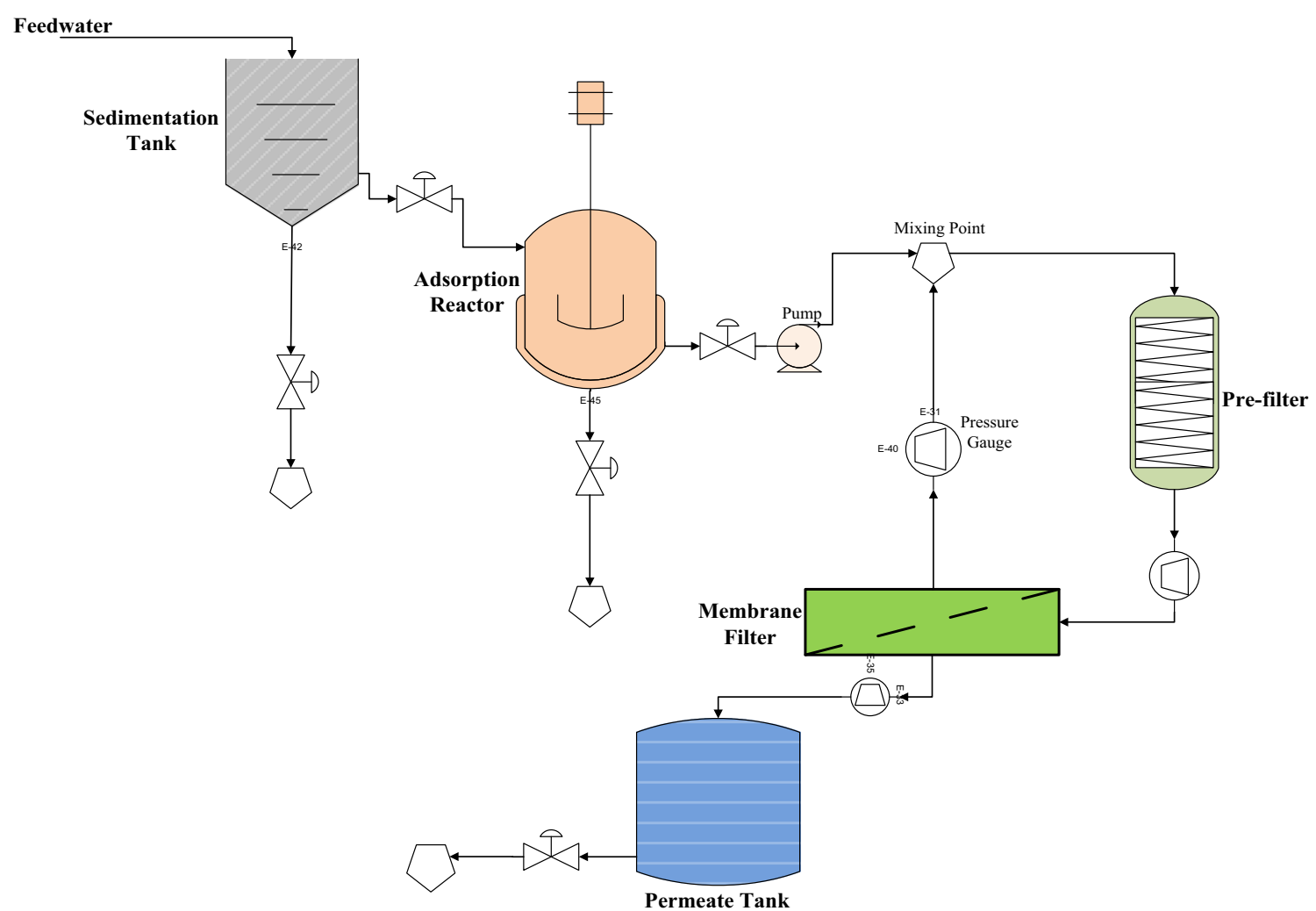

Fig. 2 Experimental unit (Amosa et al. 2016c)

first reduced with an upstream adsorption process before filtration. Powdered activated carbon (PAC) characterized of a high surface area of $886.2 \mathrm{~m}^{2} / \mathrm{g}$ with functional groups was employed in the adsorption process. A detailed characterization of the PAC, and how the adsorption process proceeded have been reported elsewhere (Amosa 2015b; Amosa et al. 2016b).

\section{Filtration and measurements}

The membrane filtration was conducted, in cross-flow mode, on all the UF membranes at the applied pressures or TMPs of 40,80 and $120 \mathrm{kPa}$. The chosen TMP range is well within the acceptable range for UF membranes, together with the pore sizes which were selected based on the reports from previous studies (Agbekodo et al. 1996; Baker et al. 1985; Boerlage et al. 2002; Fu et al. 1994; Jung and Kang 2003; Lee et al. 2007; Li et al. 2011; Ohn et al. 2003; Springer et al. 2013). The permeate volume $V$ at different filtration time $t$ data were recorded at each TMP, fluxes were computed, and the flux-time plots were used to evaluate the fouling propensity of the feedwater (Amosa et al. 2016a, c). Since the focus of the current study is to analyze the fouling phenomena of the feedwater, the permeate quality was not analyzed. The membranes were cleaned chemically with $1 \mathrm{~N}$ sodium hydroxide solution at
$50{ }^{\circ} \mathrm{C}$ of temperature. The cleaning was carried out with the permeate valves closed for $60 \mathrm{~min}$ at 200 and $0 \mathrm{kPa}$ of applied pressures at the inlet and retentate points, respectively, until the clean water flux/permeability was regained.

\section{Analysis of filtration phenomena}

The flux-time plots of the filtration experiments do not fully represent the fouling tendencies of the feed on the membranes. The fouling mechanism of the feed on the membranes were further evaluated using the Hermia's revised blocking filtration laws (Hermia 1982) for complete blocking, standard blocking, intermediate blocking and cake filtration models at each TMPs of 40, 80, and $120 \mathrm{kPa}$. Model Eqs. 1, 2, 3, 4, 5, 6, 7, 8 and 9 were applied in modelling the description and quantification of blocking mechanisms controlling the membrane processes.

\section{Results and discussion}

\section{Effects of upstream adsorption}

The upstream adsorption was utilized to strikingly reduce the wastewater strength thereby alleviating its fouling propensity with respect to the UF membranes during the 
downstream membrane filtration process. Extensive reports on the sorption mechanism have been reported elsewhere (Amosa 2015b, 2016; Amosa et al. 2015, 2016b, d). The profile of the feedwater before and after the adsorption is given in Table 1.

\section{Flux decline studies}

The adsorbed feedwater was employed throughout the filtration process and the results were used in plotting the flux-time correlation to evaluate the fouling propensities of the feedwater. Since the focus of the current study is on fouling analysis, it must be noted that the flux decline discussion based on the flux-time plots from the three UF membranes has not been included here as this has been fully reported in our previous work (Amosa et al. 2016c).

Summarily, the evaluative effects of the TMP on the permeate flux, and fouling tendency of the feed were conducted on the membranes, and it was observed from the plots that higher TMPs generated higher fluxes for the whole filtration time of $60 \mathrm{~min}$. It was also observed that the permeation flux $(J)$ sharply decreased with time at the inception of the filtration process, but the flux gradually attained relative stability/uniformity as the filtration proceeded at longer times. Since the pores of the UF membranes, which are usually characterized by their MWCO, are small, hence, relatively low fluxes were expected.

Similar trends were observed at all TMPs, and this indicates that the feedwater still contained some constituents that might be accumulating on the surface of the membranes, thus resulting in fouling or pore blocking. Relatively similar flux-time trends were observed in previous flux decline studies (Cai et al. 2013; Rashid et al. 2013). It was also observed that the UF membranes were

Table 1 Water quality of the feedwater before and after upstream adsorption

\begin{tabular}{lll}
\hline Constituents & $\begin{array}{l}\text { Raw } \\
\text { feedwater }\end{array}$ & $\begin{array}{l}\text { Adsorbed } \\
\text { feedwater }\end{array}$ \\
\hline Chemical oxygen demand COD, mg/L & 1387 & 198 \\
Total alkalinity, mg/L CaCO 3 & 1860 & 880 \\
Total hardness, mg/L CaCO 3 & 1680 & 440 \\
Manganese as Mn, mg/L & 2.14 & 0.1 \\
Sulphide as $\mathrm{H}_{2} \mathrm{~S}, \mathrm{mg} / \mathrm{L}$ & 0.6 & 0.05 \\
Total dissolved solids (TDS), mg/L & 970 & 820 \\
Turbidity, NTU & 840 & 53 \\
Silica, mg/L & 58 & 20 \\
Iron as Fe, mg/L & $\mathrm{ND}$ & $\mathrm{ND}$ \\
Suspended solids (SS), mg/L & 284 & 51 \\
pH, units & 8.56 & 9.2 \\
\hline
\end{tabular}

$N D$ Not detected

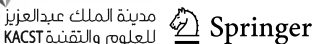

somewhat affected by the foulants contained in the feed, and this is evident from their very low fluxes. The reason for this may be attributed to the smaller pore sizes possessed by the UF membrane which lead to their higher resistances and retention capacities (Lee et al. 2007). From the foregoing, since the flux-time plots are usually employed in predicting the flux condition at long filtration times, these results indicate that the permeate flux will approach a relatively steady-state at prolonged filtration periods.

\section{Fouling phenomena studies}

In principle, governing filtration models can facilitate the design of membrane processes than any experiment can, yet, experimentations are usually required for validation reasons (Peinemann et al. 2010). To properly control particulate fouling at the design stage as well as appropriately monitor it during a plant operation, methods utilised in evaluating the particulate content of feed-water in predicting membrane fouling are essential. Declining flux with time is a phenomenon generally used in describing membrane fouling. The complete blocking, standard blocking, intermediate blocking and cake filtration mechanisms were used in studying the filtration mechanism for each of the membranes. The revised Hermia's blocking models were applied to arrive at the plots of the filtration mechanism.

For each of the membrane utilised in this investigation, the filtration blocking models were fitted to their filtration experiments performed at varying applied pressures or TMPs of 40,80 and $120 \mathrm{kPa}$. Considering all the experiments, the best fitting situations at these TMPs were selected and reported based on the highest coefficients of determination $\left(R^{2}\right)$ as the most stable for each membrane.

\section{Filtration mechanism for $1 \mathrm{kDa}$ UF membrane}

Table 2 shows the summary of all filtration model results as fitted to the filtration experiments with $1 \mathrm{kDa} U F$ membrane at all TMPs. However, only the plots that gave the best linearity (filtration model plots at $120 \mathrm{kPa}$ in this case) were reported based on $R^{2}$ values.

As observed from Table 2, the $1 \mathrm{kDa}$ UF membrane exhibited its best fitting at the TMP of $120 \mathrm{kPa}$, though not without stating the fact that the values at other TMPs of 40 and $80 \mathrm{kPa}$ were relatively close to that of $120 \mathrm{kPa}$. Similar results have been reported in previous studies (Boerlage et al. 2002; Grenier et al. 2008; Said et al. 2015). The model plots of the mechanisms at $120 \mathrm{kPa}$ are depicted in Figs. 3, 4, 5 and 6.

From the model plots, the complete blocking mechanism was experienced at the filtered volumes of 0.0082-0.0104 L, then from 0.0212 to $0.039 \mathrm{~L}$ whereas the 
Table 2 Fitting of filtration models to $1 \mathrm{kDa}$ UF membrane

\begin{tabular}{lllll}
\hline $\begin{array}{l}\text { TMP } \\
(\mathrm{kPa})\end{array}$ & \multicolumn{2}{l}{$R^{2}$ of filtration models } & & \\
\cline { 2 - 5 } & $\begin{array}{l}\text { Complete } \\
\text { blocking }\end{array}$ & $\begin{array}{l}\text { Standard } \\
\text { blocking }\end{array}$ & $\begin{array}{l}\text { Intermediate } \\
\text { blocking }\end{array}$ & $\begin{array}{l}\text { Cake } \\
\text { filtration }\end{array}$ \\
\hline 40 & 0.5384 & 0.6563 & 0.8567 & 0.9252 \\
80 & 0.532 & 0.6462 & 0.8466 & 0.9155 \\
120 & 0.5428 & 0.6591 & 0.8571 & 0.9264
\end{tabular}

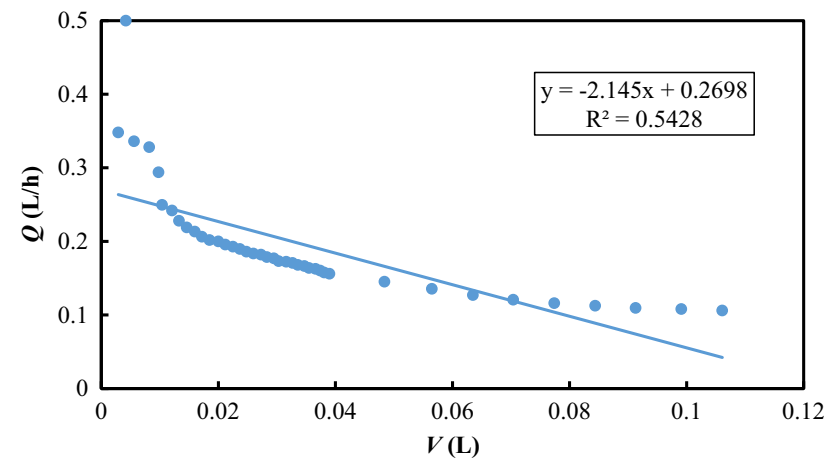

Fig. 3 Complete blocking filtration model fitted to the $1 \mathrm{kDa}$ UF membrane filtration data at $120 \mathrm{kPa}$

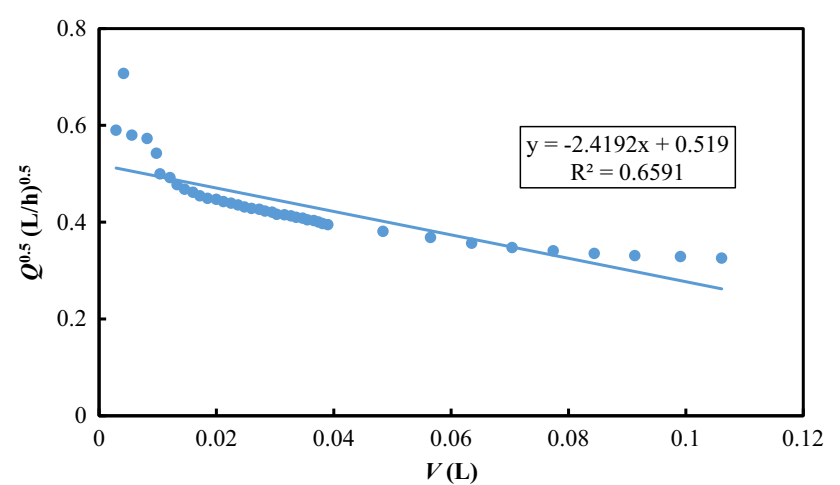

Fig. 4 Standard blocking filtration model fitted to the $1 \mathrm{kDa}$ UF membrane filtration data at $120 \mathrm{kPa}$

standard blocking mechanism contributed to the fouling only after $0.016 \mathrm{~L}$ was filtered and up to a filtration volume of $0.0381 \mathrm{~L}$ which relatively corresponds to the second phase at which the complete blockage occurred. This may be attributed to the fact that the feed-water contained more particulates that are bigger than the membrane pores, thereby leading to a more pronounced complete blocking. The core cause for such flux decline during an initial period of filtration is usually as a result of concentration polarization of solute at the membrane wall, as opined by Ghaffour (2004). It also indicates that there is little accumulation of very small particles accumulating on the walls

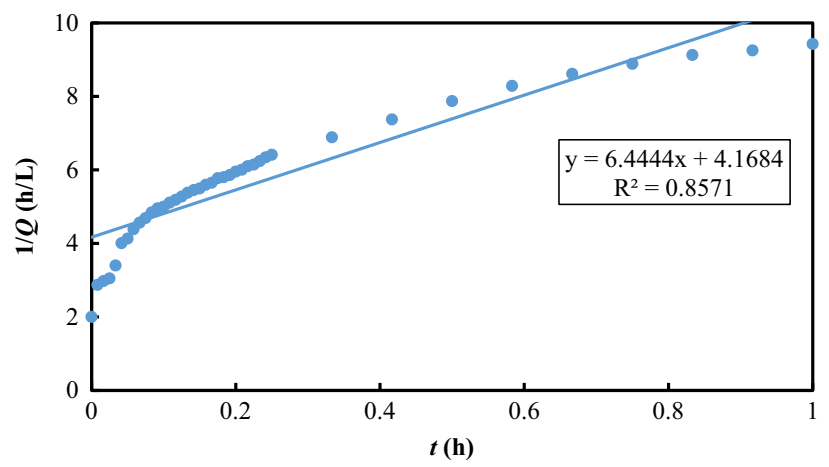

Fig. 5 Intermediate blocking filtration model fitted to the $1 \mathrm{kDa}$ UF membrane filtration data at $120 \mathrm{kPa}$

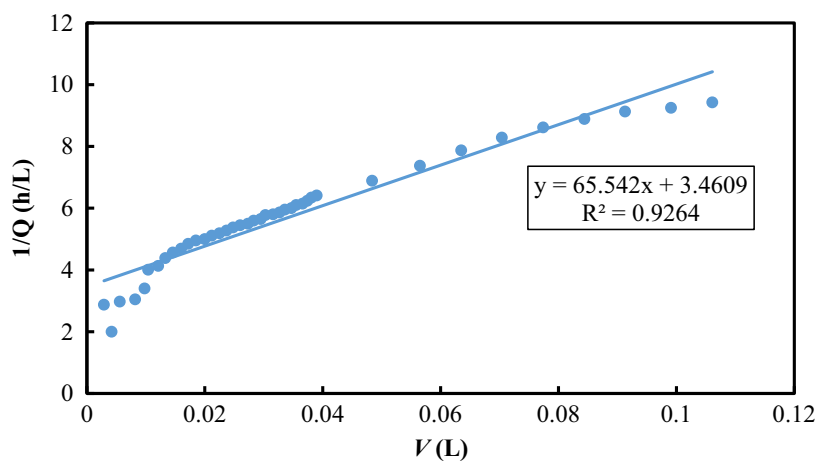

Fig. 6 Cake filtration model fitted to the $1 \mathrm{kDa}$ UF membrane filtration data at $120 \mathrm{kPa}$

of the membrane pores which might have resulted in standard blocking mechanism (Boerlage et al. 2003; Iritani 2013; Mohammadi et al. 2003). The intermediate model plot suggests that the mechanism started at a filtration time of $8 \mathrm{~min}$ and extended until $30 \mathrm{~min}$. The cake filtration mechanism started simultaneously with other mechanisms at $0.0172 \mathrm{~L}$ of filtered volume as evident from the straightest part of its plot (Fig. 6). In general, cake filtration mechanism dominated the whole filtration process as depicted by its high value of coefficient of determination. As the cake starts to be created, $V$ increased very slowly and almost independent of the pore size, given that the cake covers most of the porous area.

These results concur with previous studies (Boerlage et al. 2002; Schippers and Verdouw 1980; Yuan et al. 2002) that asserted that it is phenomenal for the complete and standard blocking mechanisms to occur at the start of a filtration because of the accumulation of particles tending towards the complete sealing of both smaller and larger pores of the membrane, progressively. After this, it is expected that the intermediate blocking takes control of the filtration mechanism for an extended period of time and serves as a transition phase between the previously occurred blocking mechanism (complete and standard) and 
Table 3 Fitting of filtration models to $5 \mathrm{kDa}$ UF membrane

\begin{tabular}{lllll}
\hline $\begin{array}{l}\text { TMP } \\
(\mathrm{kPa})\end{array}$ & \multicolumn{2}{l}{$R^{2}$ of filtration models } & & \\
\cline { 2 - 5 } & $\begin{array}{l}\text { Complete } \\
\text { blocking }\end{array}$ & $\begin{array}{l}\text { Standard } \\
\text { blocking }\end{array}$ & $\begin{array}{l}\text { Intermediate } \\
\text { blocking }\end{array}$ & $\begin{array}{l}\text { Cake } \\
\text { filtration }\end{array}$ \\
\hline 40 & 0.8532 & 0.8984 & 0.9401 & 0.9828 \\
80 & 0.8503 & 0.8976 & 0.9407 & 0.9848 \\
120 & 0.8582 & 0.905 & 0.9484 & 0.9849
\end{tabular}

cake layer stockpiling. This will continue until the establishment of a significant cake layer.

\section{Filtration mechanism for $5 \mathrm{kDa}$ UF membrane}

Table 3 shows the overall summary of the results of filtration models when fitted to the experiments with the $5 \mathrm{kDa}$ UF membrane at all TMPs.

Table 3 shows the coefficients of determination obtained from the filtration models when fitted to the experimental data with the $5 \mathrm{kDa}$ UF membrane. Similar to the $1 \mathrm{kDa}$ UF membrane, it appeared that the $5 \mathrm{kDa}$ UF membrane was also stable for the description of filtration mechanism as evident from their comparatively close $R^{2}$ values. Though all the values are very close to one another at all applied pressures, operation at the TMP of $120 \mathrm{kPa}$ gave the best fitting model plot, and it also showed that cake filtration mainly dominated in the mechanism describing the filtration process with a relatively high $R^{2}$ value of 0.9849 . Therefore, only the analysis of the filtration mechanisms based on the filtration results obtained at the TMP of $120 \mathrm{kPa}$ are presented in Figs. 7, 8, 9 and 10.

As observed from the complete and standard blocking filtration mechanisms, both mechanisms occurred simultaneously as expected with much better stability compared to what was experienced with the $1 \mathrm{kDa} \mathrm{UF}$ membrane. Complete and standard blocking started at $0.0055 \mathrm{~L}$ of filtered feed volume and persisted until the volume reached $0.036 \mathrm{~L}$ as observed from their linear plots. The intermediate blocking model, as observed from the plot, suggests that it occurred after the first $6.5 \mathrm{~min}$ and persisted until it reached $15 \mathrm{~min}$ of filtration time. The transition time for the intermediate blocking mechanism was observed to be longer compared with the $1 \mathrm{kDa}$ UF membrane. This may be due to the fact that the $5 \mathrm{kDa}$ UF membrane has a larger pore than the $1 \mathrm{kDa}$ and more filtration time and volume will be required before the particulate matters contained in the feed can be accumulated (Bacchin et al. 2006; Iritani 2013; Said et al. 2015). The cake filtration fully started after the filtrate volume of $0.04 \mathrm{~L}$ as observed from the possible straight plot that could be attained at that range.

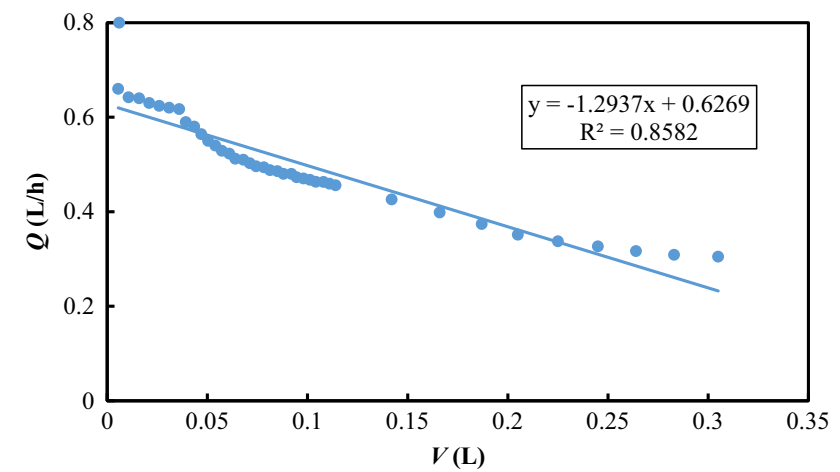

Fig. 7 Complete blocking filtration model fitted to the $5 \mathrm{kDa}$ UF membrane filtration data at $120 \mathrm{kPa}$

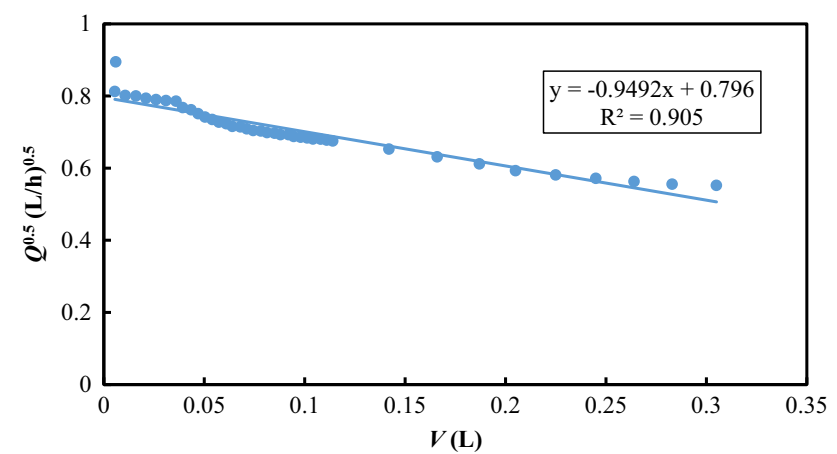

Fig. 8 Standard blocking filtration model fitted to the $5 \mathrm{kDa}$ UF membrane filtration data at $120 \mathrm{kPa}$

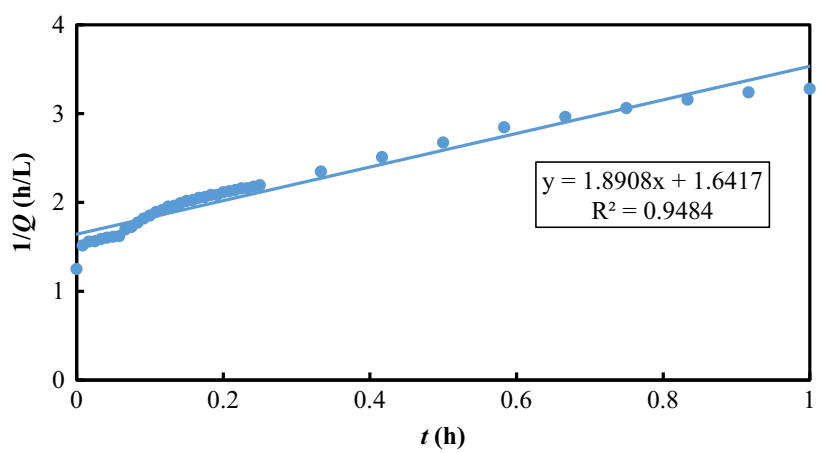

Fig. 9 Intermediate blocking filtration model fitted to the $5 \mathrm{kDa}$ UF membrane filtration data at $120 \mathrm{kPa}$

\section{Filtration mechanism for $10 \mathrm{kDa}$ UF membrane}

Table 4 shows the result summary of the filtration models when fitted to the filtration experiments with the $10 \mathrm{kDa}$ UF membrane at the TMPs of 40,80 and $120 \mathrm{kPa}$.

From Table 4, it was observed that the best stability was attained at TMP of $40 \mathrm{kPa}$ with a domineering cake filtration phenomena having the highest $R^{2}$ value of 0.9832 . Just as experienced with all other membranes, cake filtration dominated at all the TMPs, with the intermediate blocking mechanism being the closest in stability. 


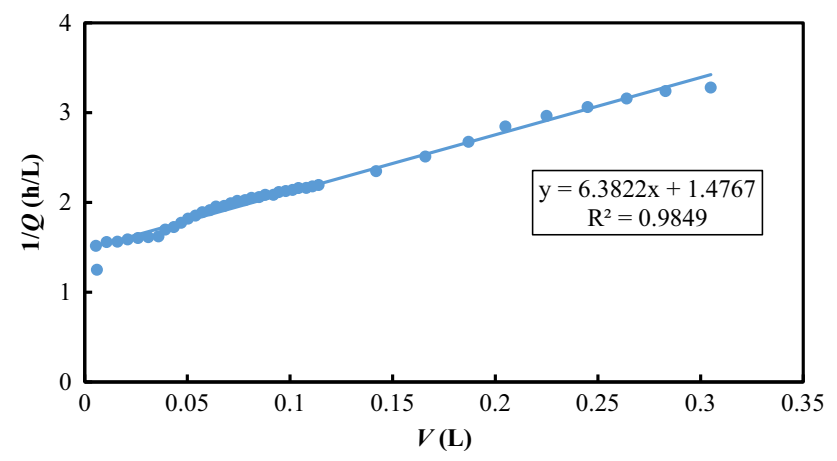

Fig. 10 Cake filtration model fitted to the $5 \mathrm{kDa}$ UF membrane filtration data at $120 \mathrm{kPa}$

Table 4 Fitting of filtration models to $10 \mathrm{kDa}$ UF membrane

\begin{tabular}{|c|c|c|c|c|}
\hline \multirow{2}{*}{$\begin{array}{l}\text { TMP } \\
(\mathrm{kPa})\end{array}$} & \multicolumn{4}{|c|}{$R^{2}$ of filtration models } \\
\hline & $\begin{array}{l}\text { Complete } \\
\text { blocking }\end{array}$ & $\begin{array}{l}\text { Standard } \\
\text { blocking }\end{array}$ & $\begin{array}{l}\text { Intermediate } \\
\text { blocking }\end{array}$ & $\begin{array}{l}\text { Cake } \\
\text { filtration }\end{array}$ \\
\hline 40 & 0.8465 & 0.8938 & 0.9383 & 0.9832 \\
\hline 80 & 0.7858 & 0.8507 & 0.9212 & 0.9783 \\
\hline 120 & 0.6497 & 0.74 & 0.8804 & 0.9483 \\
\hline
\end{tabular}

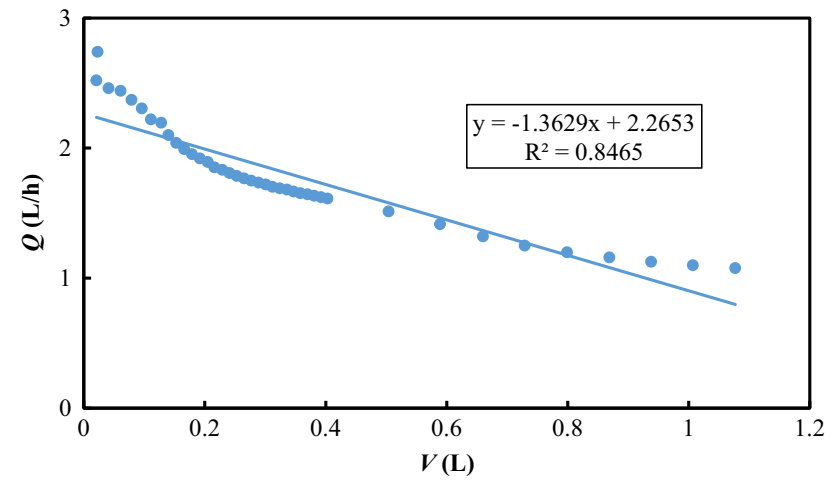

Fig. 11 Complete blocking filtration model fitted to the $10 \mathrm{kDa}$ UF membrane filtration data at $40 \mathrm{kPa}$

Figures 11, 12, 13 and 14 below depict the fouling phenomena based on the filtration results obtained at the lowest TMP of $40 \mathrm{kPa}$.

Having considered the model plots, it was noticed that the usual complete and standard blocking models were the pioneering mechanisms in the filtration process as they both simultaneously occurred between 0.0055 and $0.036 \mathrm{~L}$ of filtered volume. This phase is similar to that of the $5 \mathrm{kDa}$ UF membrane. This suggests that similar particulates are responsible for both blocking mechanisms. The intermediate blocking mechanism occurred around 6.5 until 15 min of the filtration time, while the cake filtration fully occurred after the first $0.192 \mathrm{~L}$ of permeate volume.

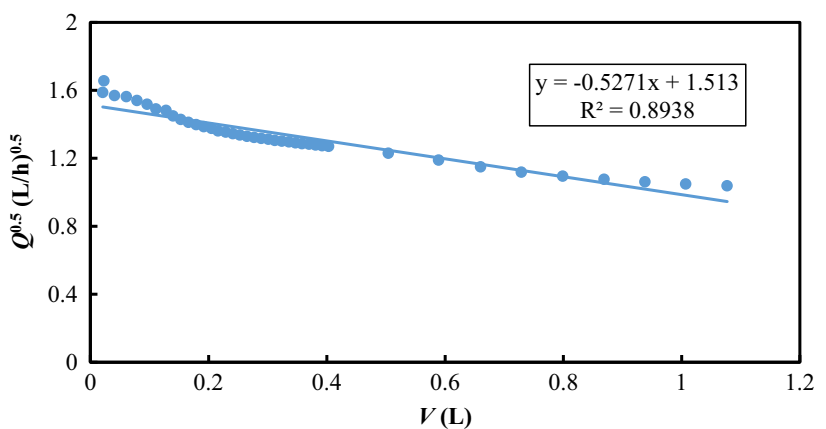

Fig. 12 Standard blocking filtration model fitted to the $10 \mathrm{kDa}$ UF membrane filtration data at $40 \mathrm{kPa}$

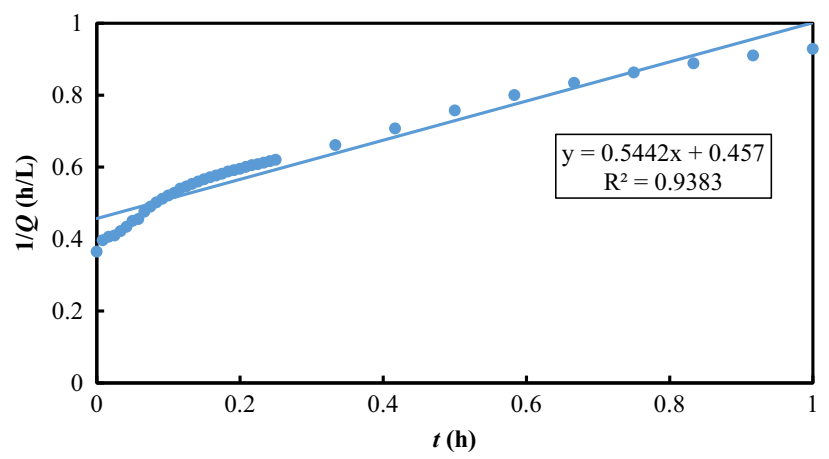

Fig. 13 Intermediate blocking filtration model fitted to the $10 \mathrm{kDa}$ UF membrane filtration data at $40 \mathrm{kPa}$

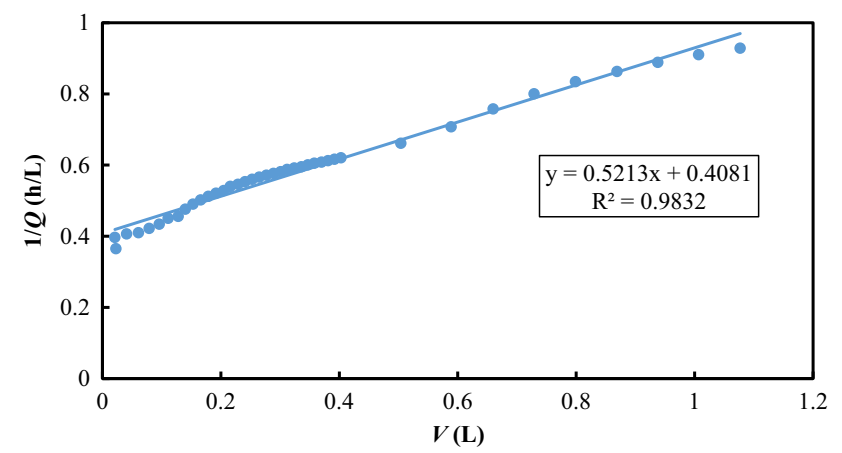

Fig. 14 Cake filtration model fitted to the $10 \mathrm{kDa}$ UF membrane filtration data at $40 \mathrm{kPa}$

All the phases occurred within those regions of straight plots from the models. Pore dimension similarity coupled with the distribution of pore size (such as heterogeneity) of 5 and $10 \mathrm{kDa}$ UF membranes may explain why some of the mechanisms occurred at same phases as opined by Boerlage et al. (2002).

Generally, it was observed that with all the filtration experiments, the flow resistance increased dramatically with time compared with the initial membrane resistance while most of the solutes passed through the membranes. 
Table 5 Summary of best fitting filtration mechanism

\begin{tabular}{lll}
\hline MWCO $(\mathrm{kDa})$ & TMP $(\mathrm{kPa})$ & $R^{2}$ for cake filtration model \\
\hline 10 & 40 & 0.9832 \\
5 & 120 & 0.9849 \\
1 & 120 & 0.9264 \\
\hline
\end{tabular}

This is obvious from the results as the onset of the filtration process is characterized of complete blocking phenomenon $(\eta=2)$, followed by the standard blocking $(\eta=1.5)$, then intermediate blocking $(\eta=1)$ and lastly the cake filtration phenomenon $(\eta=0)$. However, the cake filtration phenomenon dominated all other mechanisms as it gave the best fitting (best linearity) when fitted with the experimental data at all operating conditions. The applied pressures at which the cake filtration mechanism dominated for each of the membranes are summarized in Table 5 below. In principle, all other mechanisms also occurred at a region in a model plot but not as stable for longer periods of time or larger volumes as that of the cake filtration. Also, it could be concluded that fouling of the membranes are attributable to several more or less independent but generally coexisting phenomena.

Considering all the UF membranes, the $5 \mathrm{kDa}$ appeared to be the most stable for the filtration of biotreated POME at $120 \mathrm{kPa}$ of TMP with the highest $R^{2}$ value. The $10 \mathrm{kDa}$ UF appeared to be the closest $R^{2}$ value (Table 5). With this, the two membranes ( 5 and $10 \mathrm{kDa}$ UF) could be proposed as the promising reference membranes for use in the description of fouling mechanism for biotreated POME filtration. However, the best conclusion could only be reached after those membranes are subjected to cake compressibility evaluation tests under similar feed chemistry and operating conditions. The fitting of cake filtration model as the most universal model in describing wastewater fouling mechanism on membranes have however been reported in previous investigations (Boerlage et al. 2002, 2003; Huang et al. 2008).

\section{Conclusions}

The fouling phenomena of biotreated POME, which is a Newtonian fluid, with respect to three different MWCOs of ultrafiltration membranes have been analysed in this study to elucidate the fundamental mechanisms involved in fouling/flux decline. It was observed that the blocking index $\eta$ decreased from 2 to 0 successively as the blocking phenomenon started from complete blocking $(\eta=2)$ until a much stable phase of cake filtration phenomenon $(\eta=0)$ featured. These consecutive steps of the fouling process were elucidated in terms of the successive or simultaneous presence of the four fouling stages of complete blocking, standard blocking, intermediate blocking, and cake filtration phenomena. It was observed that the cake filtration phenomena dominated all other fouling steps though not without the other three phenomenon contributing stepwisely or simultaneously.

Since the cake deposition resulting from particulates aggregation accounted for the major flux decline, this is an indication that the fouling involved did not seriously affect the pore structure of the membrane. The 5 and $10 \mathrm{kDa}$ UF membranes were much stable at the TMP of 120 and $40 \mathrm{kPa}$, respectively, compared with the $1 \mathrm{kDa}$ UF membrane based on the $R^{2}$ values. Furthermore, with cake layer formation, it could be predicted that steady state filtration of biotreated POME could be sustainably attained at longer filtration times without a complete pore blocking. Also, fouling due to cake layer formation is reversible, and this gives an idea of the necessary cleaning methods during the stage process design. The data presented here could be employed for design upscaling to predict the fouling behaviour of such effluents when subjected to ultrafiltration processes.

Open Access This article is distributed under the terms of the Creative Commons Attribution 4.0 International License (http:// creativecommons.org/licenses/by/4.0/), which permits unrestricted use, distribution, and reproduction in any medium, provided you give appropriate credit to the original author(s) and the source, provide a link to the Creative Commons license, and indicate if changes were made.

\section{References}

Agbekodo KM, Legube B, Cote P (1996) Organics in NF permeate. J Am Water Works Assoc 88:67-74

Amosa MK (2015a) Hybrid adsorption-membrane process for reclamation of bio-treated palm oil mill effluent for boiler-feed reuse. Ph.D. Thesis, International Islamic University Malaysia, Kuala Lumpur

Amosa MK (2015b) Process optimization of $\mathrm{Mn}$ and $\mathrm{H}_{2} \mathrm{~S}$ removals from POME using an enhanced empty fruit bunch (EFB)-based adsorbent produced by pyrolysis. Environ Nanotechnol Monit Manag 4:93-105. doi:10.1016/j.enmm.2015.09.002

Amosa MK (2016) Sorption of water alkalinity and hardness from high strength wastewater on bifunctional activated carbon: process optimization kinetics and equilibrium studies. Environ Technol 37:2016-2039. doi:10.1080/09593330.2016.1139631

Amosa MK, Jami MS, Muyibi SA, Alkhatib MFR, Jimat DN (2013) Zero liquid discharge and water conservation through water reclamation \& reuse of biotreated palm oil mill effluent: a review. Int J Acad Res 5:169-182. doi:10.7813/2075-4124.2013/ $5-4 / 24$

Amosa MK, Jami MS, Alkhatib MFR, Jimat DN, Muyibi SA (2015) A two-step optimization and statistical analysis of COD reduction from biotreated POME using empty fruit bunch-based activated carbon produced from pyrolysis. Water Qual Expo Health 7:603-616. doi:10.1007/s12403-015-0176-4

Amosa MK, Jami MS, Alkhatib MF, Majozi T (2016a) Studies on pore blocking mechanism and technical feasibility of a hybrid PAC-MF process for reclamation of irrigation water from 
biotreated POME. Sep Sci Technol 51:2047-2061. doi:10.1080/ 01496395.2016.1192192

Amosa MK, Jami MS, Alkhatib MFR (2016b) Electrostatic biosorption of $\mathrm{COD}, \mathrm{Mn}$ and $\mathrm{H}_{2} \mathrm{~S}$ on EFB-based activated carbon produced through steam pyrolysis: an analysis based on surface chemistry equilibria and kinetics. Waste Biomass Valorization 7:109-124. doi:10.1007/s12649-015-9435-7

Amosa MK, Jami MS, Alkhatib MFR, Majozi T (2016c) Technical feasibility study of a low-cost hybrid PAC-UF system for wastewater reclamation and reuse: a focus on feedwater production for low-pressure boilers. Environ Sci Pollut Res. doi:10.1007/s11356-016-7390-x (in press)

Amosa MK, Jami MS, Alkhatib MFR, Tajari T, Jimat DN, Owolabi RU (2016d) Turbidity and suspended solids removal from highstrength wastewater using high surface area adsorbent: mechanistic pathway and statistical analysis. Cogent Eng 3:1162384. doi:10.1080/23311916.2016.1162384

Bacchin P, Aimar P, Field RW (2006) Critical and sustainable fluxes: theory, experiments and applications. J Membr Sci 281:42-69

Baker R, Fane A, Fell C, Yoo B (1985) Factors affecting flux in crossflow filtration. Desalination 53:81-93

Boerlage SF, Kennedy MD, Dickson MR, El-Hodali DE, Schippers JC (2002) The modified fouling index using ultrafiltration membranes (MFI-UF): characterisation, filtration mechanisms and proposed reference membrane. J Membr Sci 197:1-21

Boerlage SF, Kennedy MD, Aniye MP, Abogrean E, Tarawneh ZS, Schippers JC (2003) The MFI-UF as a water quality test and monitor. J Membr Sci 211:271-289

Bowen W, Calvo J, Hernandez A (1995) Steps of membrane blocking in flux decline during protein microfiltration. $\mathrm{J}$ Membr Sci 101:153-165

Cai M, Wang S, Liang H (2013) Modeling and fouling mechanisms for ultrafiltration of Huanggi (Radix astragalus) extracts. Food Sci Biotechnol 22:407-412. doi:10.1007/s10068-013-0094-9

Fatta-Kassinos D, Michael C (2013) Wastewater reuse applications and contaminants of emerging concern. Environ Sci Pollut Res 20:3493-3495. doi:10.1007/s11356-013-1699-5

Fu P, Ruiz H, Thompson K, Spangenberg C (1994) Selecting membranes for removing NOM and DBP precursors. J Am Water Works Assoc 86:55-72

Ghaffour N (2004) Modeling of fouling phenomena in cross-flow ultrafiltration of suspensions containing suspended solids and oil droplets. Desalination 167:281-291. doi:10.1016/j.desal.2004. 06.137

Grenier A, Meireles M, Aimar P, Carvin P (2008) Analysing flux decline in dead-end filtration. Chem Eng Res Des 86:1281-1293. doi:10.1016/j.cherd.2008.06.005

Hermans PH, Bredée HL (1935) Zur Kenntnis derder Filtrationsgesetze. Rec Trav Chim Pays Bas 54:680

Hermans PH, Bredée HL (1936) Principles of the mathematical treatment of constant pressure filtration. J Soc Chem Ind 55:1-4

Hermia J (1966) Etude analytique des lois de filtration a pression constante. Rev Univ Mines 2:45-51

Hermia J (1982) Constant pressure blocking filtration law: Application to power-law non-Newtonian fluid. Trans Inst Chem Eng 60:183-187
Huang H, Young TA, Jacangelo JG (2008) Unified membrane fouling index for low pressure membrane filtration of natural waters: principles and methodology. Environ Sci Technol 42:714-720

Iritani E (2013) A review on modeling of pore-blocking behaviors of membranes during pressurized membrane filtration. Dry Technol 31:146-162

Jami MS, Amosa MK, Alkhatib MFR, Jimat DN, Muyibi SA (2013) Boiler-feed and process water reclamation from biotreated palm oil mill effluent (BPOME): a developmental review. Chem Biochem Eng Q 27:477-489

Judd S (2011) The MBR book: principles and applications of membrane bioreactors for water and wastewater treatment, 2nd edn. Elsevier, UK

Jung CW, Kang LS (2003) Application of combined coagulationultrafiltration membrane process for water treatment. Korean $\mathrm{J}$ Chem Eng 20:855-861

Lee CW, Bae SD, Han SW, Kang LS (2007) Application of ultrafiltration hybrid membrane processes for reuse of secondary effluent. Desalination 202:239-246

Li Y, Wang J, Zhang W, Zhang X, Chen C (2011) Effects of coagulation on submerged ultrafiltration membrane fouling caused by particles and natural organic matter (NOM). Chin Sci Bull 56:584-590

Mohammadi T, Kazemimoghadam M, Saadabadi M (2003) Modeling of membrane fouling and flux decline in reverse osmosis during separation of oil in water emulsions. Desalination 157:369-375

Ohn T, Jami M, Iritani E, Mukai Y, Katagiri N (2003) Filtration behaviors in constant rate microfiltration with cyclic backwashing of coagulated sewage secondary effluent. Sep Sci Technol 38:951-966

Peinemann K-V, Nunes SP, Giorno L (2010) Membranes for food applications vol 3. Membrane technology. WILEY-VCH Verlag GmbH \& Co. KGaA, Weinheim

Rashid SS, Alam MZ, Fazli MBFA (2013) Separation of cellulase enzyme from fermentation broth of palm oil mill effluent by ultrafiltration process. Int J Chem Environ Biol Sci 1:501-506

Rezaei H, Ashtiani FZ, Fouladitajar A (2014) Fouling behavior and performance of microfiltration membranes for whey treatment in steady and unsteady-state conditions. Braz J Chem Eng 31:503-518. doi:10.1590/0104-6632.20140312s00002521

Said M, Ahmad A, Mohammad AW, Mohd Nor MT, Sheikh Abdullah SR (2015) Blocking mechanism of PES membrane during ultrafiltration of POME. J Ind Eng Chem 21:182-188. doi:10.1016/j.jiec.2014.02.023

Schippers JC, Verdouw J (1980) The modified fouling index, a method of determining the fouling characteristics of water. Desalination 32:137-148. doi:10.1016/S0011-9164(00)86014-2

Springer F, Laborie S, Guigui C (2013) Removal of $\mathrm{SiO}_{2}$ nanoparticles from industry wastewaters and subsurface waters by ultrafiltration: investigation of process efficiency, deposit properties and fouling mechanism. Sep Purif Technol 108:6-14

Yuan W, Kocic A, Zydney AL (2002) Analysis of humic acid fouling during microfiltration using a pore blockage-cake filtration model. J Membr Sci 198:51-62 